\title{
Práticas Informacionais de Blogueiros Literários
}

\author{
Jéssica Patrícia Silva de Sá \\ Mestra; Universidade Federal de Minas Gerais, Belo Horizonte, MG, Brasil \\ j.jessicadesa@gmail.com \\ Carlos Alberto Ávila Araújo \\ Doutor; Universidade Federal de Minas Gerais, Belo Horizonte, MG, Brasil; \\ casalavila@yahoo.com.br
}

\begin{abstract}
Resumo: Nesse artigo são apresentados os resultados de uma investigação que buscou averiguar as práticas informacionais dos blogueiros literários no que diz respeito aos seus papéis como leitores, produtores de conteúdo e mediadores de leitura nos webrings - os círculos sociais de blogueiros - pertencentes à blogosfera literária. Por se tratar de uma pesquisa de cunho qualitativo em profundidade, a metodologia consistiu no uso da netnografia, que possibilitou uma imersão na blogosfera literária, utilizando-se a análise documental e a entrevista semiestruturada como técnicas de coleta de dados. Os resultados apontaram as práticas informacionais realizadas pelas oito blogueiras identificadas na amostra, que foram elencadas em quatro categorias: leitura, identidade, ações de informação e interação. A respeito dos papéis exercidos pelas blogueiras na blogosfera literária, identificou-se que elas atuam como leitoras e como produtoras de conteúdo, não sendo consideradas como mediadoras de leitura, apesar de incentivarem a leitura em seus blogs. A motivação de cada blogueira tanto para adentrar na blogosfera literária como para manter seu blog ativo perpassa por questões pessoais, que vão além da simples vontade de compartilhar leituras: a necessidade de trabalhar a timidez, ter voz ativa e ser ouvida por outras pessoas, poder expressar sua opinião sobre as leituras, ser um exemplo para os filhos e mantê-los próximos, escapar da solidão, a responsabilidade com as parcerias editoriais e com os leitores do blog. No que tange à formação dos webrings, constatou-se que eles são formados tanto de forma virtual como presencial, por meio dos eventos literários. Contudo, a interação entre os blogueiros literários ocorre predominantemente no meio virtual.
\end{abstract}

Palavras-chave: Práticas Informacionais. Blogs literários. Blogueiros. Webrings. Compartilhamento de leituras 


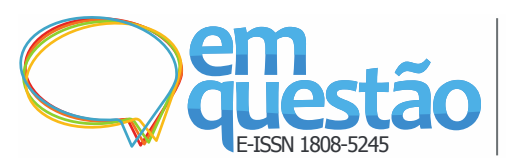

\section{Introdução}

Em outras épocas, para que um leitor pudesse compartilhar suas leituras era necessário um local onde um grupo de leitores pudesse se encontrar pessoalmente. Outro meio de comunicação era o envio de correspondências por correio para compartilhar leituras, críticas e comentários. O advento da internet abriu novas possibilidades para entrar em contato com as pessoas através da rede. Assim, uma comunidade de leitores não precisa ser necessariamente um encontro de um grupo in loco. Atualmente, a interação ocorre de forma on-line, onde leitores podem elogiar, sugerir, opinar e criticar sobre o que leram durante ou imediatamente após a leitura (CARNEIRO, 2011). Dessa forma, surgiram espaços virtuais nos quais leitores podem compartilhar suas leituras, opiniões, críticas, sugestões e quaisquer informações literárias. Um desses espaços são os blogs literários.

De modo geral, um blog se configura como um espaço virtual utilizado para publicação de informação escrita dos mais diversos gêneros. Conforme Pereira (2008), as principais características de um blog são a atualização constante e o formato de diários com textos, notícias e opiniões individualizadas e com estilo informal e subjetivo. Ao se tratar especificamente da literatura, é possível encontrar inúmeros blogs literários que se dedicam a compartilhar informações sobre o tema. Rafaela Araújo e Ronaldo Araújo (2015) consideram blogs literários como aqueles que abordam de várias maneiras a temática da leitura, dos livros e da literatura em geral. De acordo com esses autores, a resenha seria um elemento importante na categorização dos blogs literários, pois são as representações das experiências de leitura do blogueiro, transmitidas aos leitores da página.

Outra importante característica de um blog diz respeito à interatividade, que se dá através dos comentários possíveis de serem feitos nas postagens. Recuero (2003) denomina esses círculos sociais formados por blogueiros como webrings, que "[...] representam um círculo de pessoas que interagem com alguma frequência através de seus blogs e comentários.” (RECUERO, 2003, p. 9, grifo nosso). 


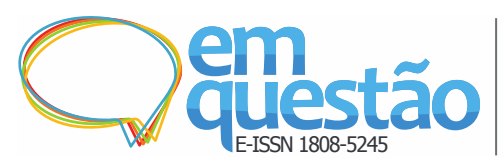

Com base nos argumentos elencados, esse artigo tem como objetivo investigar os blogs literários buscando averiguar as práticas informacionais dos blogueiros no que diz respeito aos seus papéis como leitores, produtores de conteúdo e mediadores de leitura nos webrings pertencentes à blogosfera literária. Para alcançar o objetivo geral, foram considerados os seguintes objetivos específicos: caracterizar as práticas informacionais dos blogueiros literários; constatar os principais motivos que levam à criação do blog literário; identificar os papéis dos blogueiros literários como leitores, produtores de conteúdo e mediadores de leitura nos webrings; investigar como se dá a criação dos webrings.

Assim sendo, a compreensão das práticas informacionais desses sujeitos pode fornecer importantes elementos para o entendimento das maneiras como círculos sociais lidam com a informação nos blogs disponíveis na web. Tal estudo pretende ampliar a agenda do campo dos estudos de usuários da informação, que historicamente sempre privilegiou certos grupos sociais, como cientistas, empresários e profissionais. A ampliação dessa agenda de pesquisas possibilita que outros grupos sociais sejam contemplados nos estudos realizados na Ciência da Informação (CI), considerando outros tipos de sujeitos informacionais (ARAÚJO, C., 2008).

\section{Práticas Informacionais}

Ao analisar a perspectiva histórica da CI, Capurro (2003) apresenta os três paradigmas epistemológicos da Ciência da Informação: paradigma físico, cognitivo e social. O paradigma físico remete à teoria matemática e à concepção de informação como coisa, um fenômeno objetivo, excluindo-se o papel ativo do usuário na recuperação de informações e no processo informativo e comunicativo em geral. O paradigma cognitivo pretende compreender de que maneira os processos informativos transformam o usuário, tido como um indivíduo cognitivo portador de uma necessidade, uma anormalidade cognitiva em que os conhecimentos que possui não são suficientes para resolver um problema. O paradigma social não compreende o usuário como um ser isolado, 


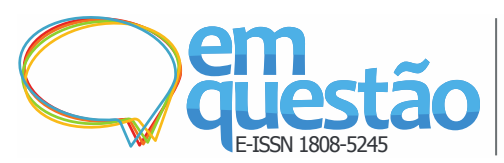

mas inserido em um contexto social, que desempenha um papel ativo em sua relação com a informação.

Esses diferentes contextos históricos e científicos possibilitaram o surgimento de determinadas maneiras de se estudar os usuários da informação. Dessa forma, é possível identificar o percurso dos estudos de usuários da informação dentro dos paradigmas físico, cognitivo e social, tratando-se respectivamente das abordagens tradicional, alternativa e social.

A abordagem social, adotada nessa pesquisa, refere-se ao terceiro paradigma, identificado por Capurro (2003) como paradigma social. Para o autor, esse paradigma é importante ao transcender os limites impostos pelo paradigma cognitivo, que considera a informação como algo separado do usuário, considerando-o primordialmente como sujeito cognoscente, isolado das condições sociais e materiais da existência humana. Conforme Capurro (2003), deve existir uma integração da perspectiva individualista e isolacionista do paradigma cognitivo dentro de um contexto social. Para ele, a informação só tem valor enquanto conhecimento quando compartilhada, com a possibilidade de se apresentar relevante para outros indivíduos ou grupos.

No contexto da abordagem social dos estudos de usuários da informação surgem estudos de práticas informacionais, em oposição aos estudos de comportamento informacional da abordagem alternativa. De acordo com Sirihal Duarte, Carlos Araújo e Paula (2017), a adoção do termo práticas informacionais e dos estudos voltados para uma postura sociocultural fazem parte de um momento histórico de valorização do contexto das investigações. $\mathrm{O}$ usuário da informação passa a ser denominado sujeito informacional, termo que ressalta seu caráter de ator. Dessa forma, essa perspectiva considera as relações dialógicas entre o sujeito e o contexto. A terminologia práticas informacionais denomina “[...] os estudos conduzidos a fim de investigar como se dão os interrelacionamentos entre o sujeito e a informação." (SIRIHAL DUARTE; ARAÚJO, C.; PAULA, 2017, p. 3).

Os estudos de práticas informacionais concentram-se em compreender os indivíduos como membros de vários grupos e comunidades que constituem o contexto de sua vida e atividades cotidianas. A ênfase é no papel dos fatores 


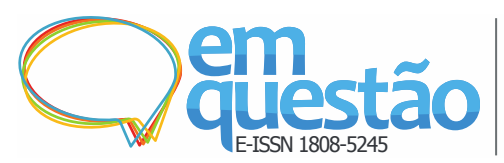

contextuais que permeiam a busca, uso e compartilhamento de informações, o que difere das abordagens individualistas e descontextualizadas, como é o caso dos estudos de comportamento informacional. As práticas informacionais também podem lidar com elementos da comunicação e não apenas com a busca por informações. Desse modo, a fronteira entre comunicação e informação é difícil de ser delimitada, podendo sobrepor-se em muitos casos, como nos estudos de contextos interacionais de informação (SAVOLAINEN, 2007).

Constata-se que o conceito de práticas informacionais, ainda em construção, apresenta novas perspectivas para o estudo dos usuários, agora compreendidos como sujeitos informacionais. Os estudos de práticas informacionais não analisam a sequência linear de necessidade, busca e uso de informação. As práticas informacionais consistem nos diversos modos como os sujeitos lidam com a informação, que nem sempre partem de uma necessidade específica, considerando-se o encontro ocasional com a informação. A busca e o uso da informação apresentam-se socialmente inseridos, permeados por processos comunicativos, que envolvem a interação entre os sujeitos e o compartilhamento de informações.

\section{Blogs literários}

Os sujeitos informacionais da presente pesquisa são os blogueiros literários e seus respectivos blogs. São considerados blogs literários, como o próprio nome sugere, blogs que abordam de várias maneiras a temática da leitura, dos livros e da literatura em geral (ARAÚJO, Rafaela; ARAÚJO, Ronaldo, 2015). O objetivo dos blogs literários geralmente é promover o hábito da leitura e proporcionar um diálogo em torno dos livros, que vão dos clássicos aos lançamentos modernos (SANTOS; RODRIGUES; FERREIRA, 2014). Assim, os blogs literários levam uma discussão sobre livros e literatura para o ambiente virtual.

De acordo com Silva e Martha (2010) a literatura se inseriu no ciberespaço como forma de buscar sua sobrevivência e, principalmente, conquistar mais leitores. 
Assim, observando este novo leitor, a literatura criou diversos espaços no mundo eletrônico e entre estas diversas formas de veiculação de textos na internet, o blog é um dos mais procurados e tem interessado tanto os leitores como os estudiosos. (SILVA; MARTHA, 2010, p. 4, grifo nosso).

As resenhas apresentam-se como um importante elemento na caracterização de um blog literário. Outra característica comumente presente nesse tipo de blog são notícias sobre lançamentos de livros, novidades sobre autores e eventos do gênero. Um elemento comum nos blogs literários são as parcerias, entre blogs e também entre editoras. A parceria entre blogs funciona como uma troca de divulgações e a parceria entre editoras consiste no envio de livros como cortesia, assim o blogueiro se compromete a resenhá-los em seu blog (ARAÚJO, Rafaela; ARAÚJO, Ronaldo, 2015).

A interatividade é uma das principais características dos blogs, de forma que os blogueiros literários interagem entre si, formando círculos sociais na web, os denominados webrings.

\subsection{Webrings}

Os blogueiros estabelecem relações virtuais entre si, ao lerem mutualmente seus blogs e entrarem em contato por meio de comentários. Segundo Recuero (2003), dessas relações virtuais surgem os webrings, compostos não apenas pelo blog, mas também pelo círculo de blogueiros e pelos comentários sobre o blog, além do suporte tecnológico e da comunidade virtual.

[...] utilizamos o termo webring para definir círculos de bloggeiros que lêem seus blogs mutuamente e interagem nestes blogs através de ferramentas de comentários. Os blogs são linkados uns nos outros e formam um anel de interação diária, através da leitura e do comentário dos posts entre os vários indivíduos, que chegam a comentar os comentários uns dos outros ou mesmo deixar recados para terceiros nos blogs. Esse círculo de blogs difere, basicamente, de um grupo de links porque, como discutiremos adiante, o blog funciona como uma representação do bloggeiro no ciberespaço. Portanto, num webring, como o definimos aqui, temos um grupo de pessoas, mais do que um grupo de links. (RECUERO, 2003, p. 7, grifo nosso).

Em um primeiro momento, o leitor conhece o blog, ao ler os posts sente a necessidade de interagir com o autor e deixar comentários. Aos poucos, esse 


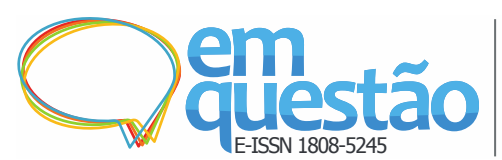

leitor vai conhecendo o autor e percebendo que outros leitores também interagem com ele. O leitor, muitas vezes, também possui um blog, onde também tem contato com seus respectivos leitores. É assim que o círculo começa a ser formado (RECUERO, 2003).

Blogueiros são como vizinhos, visitam-se diariamente, leem os posts uns dos outros e interagem por meio de comentários. As visitas recíprocas a partir dos links disponíveis nos blogs é que possibilitam a qualidade dinâmica dos mesmos (DI LUCCIO; NICOLACI-DA-COSTA, 2010). É assim que são constituídos os webrings.

\section{Ler e compartilhar}

Ao abordar como objeto empírico os blogueiros literários e seus respectivos blogs, torna-se necessário trabalhar questões relativas à leitura literária, uma vez que essa está vinculada ao motivo da existência dos blogs literários.

A leitura literária se mostra paradoxal, conforme Petit (2009), pois permite escapadas solitárias e também encontros. Ao tratar do ato da leitura solitária, a autora considera que os livros podem auxiliar a manter o medo à distância, podendo também transformar a dor e agonia, possibilitando o reencontro com a alegria. Entende-se que a leitura permite ao leitor conhecer sua própria interioridade, tendo os livros como reflexos de si mesmo ao encontrar neles pensamentos e lembranças. Além disso, o leitor vivencia a alteridade, muda seu ponto de vista, coloca-se no lugar do outro. A leitura também possibilita ao leitor conectar-se à humanidade, identificando sentimentos e experiências comuns aos seres humanos. Por outro lado, Bértolo (2014) afirma que a leitura silenciosa apresenta a possibilidade e o risco de que o leitor acredite que é ele quem dá vida às palavras e que o texto foi escrito somente para ele. Assim, o leitor silencioso tende a se apropriar das palavras de maneira individual, singular, própria, particular, egoísta e narcisista. Em decorrência desses sentimentos, é compreensível que um caminho possível para o leitor seja buscar outros leitores, procurando compartilhar suas leituras e experiências.

Adentrando na dimensão da leitura literária compartilhada, Petit (2009) afirma que aquelas e aqueles que participam de espaços de leitura livremente 


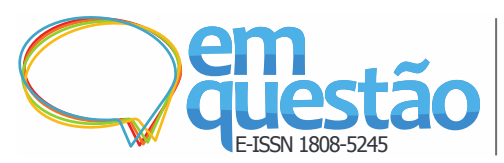

compartilhadas adquirem melhores possibilidades de se expressar. Por um lado, nesses espaços os leitores se sentem vinculados aos outros, descobrindo que dividem as mesmas emoções e confusões; por outro lado, eles se veem separados, capazes de pensar independentemente, o que propicia a delimitação de si mesmo, permitindo a cada leitor traçar os seus próprios contornos.

Em geral, os encontros presenciais oferecem trocas riquíssimas entre os leitores, de forma que sua importância não deve ser menosprezada. Entretanto, a web abre outra possibilidade: o leitor tem a oportunidade de se conectar com outros leitores através da rede. Assim, se no passado só era possível formar uma comunidade de leitores a partir de encontros presenciais, atualmente a internet permite a interação entre leitores por meio de ambientes virtuais que proporcionam um diálogo sobre livros e literatura.

Em virtude desse novo leitor/internauta, surgiram também novas ferramentas e plataformas que proporcionassem espaços para as discussões e trocas literárias. Em relação a essa temática, Gnisci (2018, p. 110, grifo nosso) considera que "Quanto às produções e críticas literárias, o blog pode ser considerado a primeira ferramenta midiática a compartilhar relatos de experiências individuais e coletivos de diversas áreas [...]". Além dos blogs literários, existem outros espaços virtuais nos quais acontecem trocas literárias. Algumas plataformas proporcionam a formação de comunidades virtuais de leitores: Facebook, YouTube, Instagram, Twitter, Skoob, Wattpad.

É interessante ressaltar que esses espaços são, de certa forma, complementares, uma vez que o fato de um leitor ter um perfil em uma determinada rede não impede que ele possa criar o perfil em outra plataforma. $\mathrm{O}$ que acontece é justamente o contrário: é comum o leitor literário participar de mais de uma rede social sobre leitura. Conforme Arnaut et al. (2011, p. 5), vivemos atualmente em uma "era transmídia", com a disponibilidade de diversas plataformas e meios de comunicação nos quais a população pode engajar-se, interagir e gerar conteúdo.

Sempre que há o engajamento por determinado assunto, e é feita a distribuição de forma conectada entre as múltiplas plataformas de mídia, pode-se observar a transmídia em ação, seja de forma planejada ou por consequência das mídias espontâneas [...] (ARNAUT et al., 2011, p. 5). 


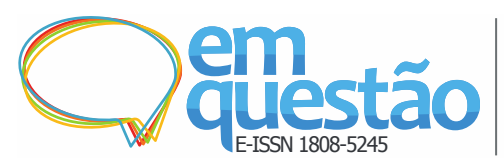

Em suma, as redes estão todas interligadas, o que proporciona ao leitor literário espaços virtuais diversos nos quais ele pode escolher a forma como quer interagir e transmitir suas experiências literárias. O leitor poderá ainda optar pela criação de conteúdos textuais, imagéticos e audiovisuais, divulgando sua produção nas diversas mídias disponíveis na web.

\section{Metodologia}

Para o desenvolvimento da pesquisa1 optou-se por utilizar o método da netnografia. A internet proporciona um novo meio para troca social, para Kozinets (2002) uma reunião social mediada por computador constitui uma comunidade on-line. Dessa forma, a netnografia apresenta-se como a adaptação do método etnográfico para o estudo de comunidades virtuais. Assim como a etnografia, a netnografia também é bastante flexível e adaptável.

A netnografia baseia-se principalmente na observação do discurso textual, seu foco está nos laços particulares dos grupos e a profundidade reveladora de suas comunicações on-line. Conclusões úteis podem ser retiradas de um número relativamente pequeno de mensagens, caso essas contenham informações descritivas suficientes para serem interpretadas com considerável profundidade analítica e percepção (KOZINETS, 2002).

Ao se tratar de um estudo de cunho qualitativo em profundidade, pautado no método netnográfico, optou-se por adotar as seguintes técnicas de coletas de dados: análise documental e entrevista semiestruturada.

O método etnográfico pressupõe a técnica da observação como forma de compreensão e análise dos fenômenos. Como afirmado anteriormente, no caso da netnografia, a observação baseia-se principalmente na observação do discurso textual, objetivando compreender as relações sociais dos grupos e a profundidade de suas comunicações virtuais (KOZINETS, 2002). Dessa forma, a observação netnográfica nessa pesquisa foi embasada nos preceitos da análise documental. Com base nesses pressupostos, após a seleção da amostra dos blogs que foram investigados, a primeira etapa da coleta de dados consistiu em uma imersão na blogosfera literária. A partir dela, foi possível conhecer os blogs e os blogueiros, realizando a leitura de postagens e comentários. Ao analisar o 


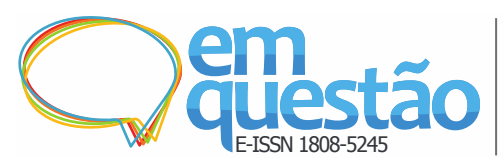

conteúdo textual, imagético e hipertextual presente nos blogs, buscou-se compreender como se configura o perfil de cada blog e que tipo de informação é veiculada pelo blogueiro.

Como complementação da análise documental, foram aplicadas entrevistas semiestruturadas. Dessa forma, a segunda etapa da coleta de dados consistiu na realização das entrevistas semiestruturadas com os blogueiros responsáveis pelos blogs selecionados para a pesquisa, buscando entender as práticas do sujeito informacional do seu ponto de vista. Por meio de tais entrevistas pretendeu-se apreender as falas dos sujeitos no que se refere às intenções de criação do blog, como acontecem as interações entre os blogueiros possibilitando a formação dos webrings, e como o blogueiro se identifica como leitor literário, produtor de conteúdo e também como mediador de leitura na blogosfera literária. O roteiro da entrevista semiestruturada foi elaborado em dois blocos:

a) o blogueiro e sua relação com seu blog: visou coletar dados referentes aos blogueiros e seus blogs, objetivando conhecer aspectos pessoais desses sujeitos como suas práticas de leitura literária e aspectos relacionados à criação do blog (motivação pessoal, influências, necessidade de compartilhar leituras etc.), além da relação do blogueiro com o blog;

b) o blogueiro e a interatividade: no intuito de coletar dados referentes às práticas informacionais dos blogueiros, verificando como o blogueiro, considerado sujeito informacional, atua na blogosfera literária, objetivando identificar como ocorre a interação entre os blogueiros e a formação dos webrings. Intencionou também obter dados sobre o papel do blogueiro como produtor de conteúdo, sendo escritor do seu próprio blog, além de seu possível papel de mediador de leitura.

O universo da pesquisa abrangeu os blogueiros literários da Região Metropolitana de Belo Horizonte (RMBH) e seus respectivos blogs. A opção do recorte por localização geográfica é justificada pela preferência em realizar a entrevista de forma presencial, o que possibilita um contato maior com os 


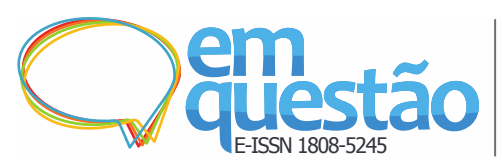

entrevistados, considerando-se que o método de coleta de dados adotado exige maior profundidade.

Quanto à amostra, Guerra (2006) afirma que não faz muito sentido falar de amostragem em uma pesquisa qualitativa, uma vez que não se procura uma representatividade estatística, mas sim uma representatividade social. De acordo com a autora, nas pesquisas qualitativas a maioria dos autores utiliza a noção de amostra em um sentido não probabilístico.

Dessa forma, a amostra de blogueiros literários foi definida em um evento literário, o $20^{\circ}$ \#Clube do Livro $\mathrm{BH}$, que aconteceu no dia 24 de fevereiro de 2018. Das 196 pessoas presentes no evento, foram identificadas 19 pessoas que afirmaram ter um blog literário. Dessa forma, dos 19 blogs identificados, oito blogs foram considerados como possíveis de serem contemplados na pesquisa. Os demais 11 blogs foram desconsiderados, uma vez que suas características não estavam em conformidade com a definição de blog literário adotada.

A amostra constitui-se dos seguintes blogs literários: Entrando Numa Fria, Minha Estante e Muito Mais, Marshmallow com Café, DNA Literário, Cultura Pocket, Menina Compassiva, Livros e Sushi, Paradise Books.

As blogueiras administradoras desses oito blogs foram contactadas virtualmente, sendo convidadas para fornecerem entrevistas. As entrevistas foram realizadas pessoalmente no período de 19/06/2018 a 28/07/2018, sendo gravadas e, posteriormente, transcritas na íntegra pela própria pesquisadora.

A faixa etária das entrevistadas foi de 20 a 36 anos. Todas as blogueiras residem na RMBH, sendo que cinco moram na cidade de Belo Horizonte, duas em Ribeirão das Neves e uma em Contagem. Quanto à escolaridade, três possuem o ensino superior incompleto, sendo estudantes de graduação. As outras cinco possuem ensino superior completo, dentre elas uma possui pósgraduação. Em relação à profissão, as blogueiras possuem ocupações que não estão vinculadas à literatura. Curiosamente, essas leitoras atuam profissionalmente sem contato direto com a leitura literária. Entre as três estudantes, uma cursa Fisioterapia, uma Jornalismo e a outra Design Gráfico. Entre as outras cinco, identificou-se: uma advogada, uma analista contábil, uma 


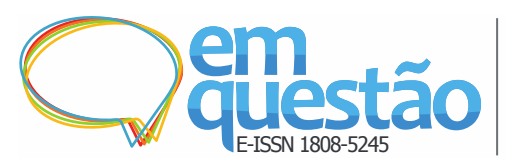

administradora de empresas, uma analista de processos e uma professora de circo.

No que tange ao ano em que se tornaram blogueiras, algumas criando seu próprio blog e outras se inserindo em blogs já existentes, todas adentraram na blogosfera literária na última década. A mais experiente é blogueira desde 2008 e a menos experiente tornou-se blogueira em janeiro de 2018.

Para analisar os dados obtidos nas entrevistas, realizou-se a análise de conteúdo das falas das entrevistadas. De acordo com Franco (2005), a análise de conteúdo é utilizada para produzir inferências acerca de dados verbais ou simbólicos, coletados por meio de perguntas e observações feitas pelo pesquisador. Segundo a autora, o ponto de partida da análise de conteúdo é a mensagem emitida, vinculada às condições contextuais de seus produtores, pois as expressões verbais estão permeadas de componentes cognitivos, afetivos, valorativos, históricos e ideológicos. "É, portando, com base no conteúdo manifesto e explícito que se inicia o processo de análise [...]" (FRANCO, 2005, p. 24). Para Franco (2005), a produção de inferências é essencial na análise de conteúdo, uma vez que a ação puramente descritiva é de pequeno valor. As inferências permitem a criação de relações entre os dados, assim toda análise de conteúdo implica em comparações, inclusive com abordagens teóricas.

\section{Resultados e discussão}

A análise documental foi realizada por meio do acompanhamento e leitura das postagens dos blogs, sendo também analisados os layouts dos blogs e os recursos disponíveis. Em um período de seis meses, compreendido entre março e agosto de 2018, foi observado em cada um dos blogs o conteúdo textual, o conteúdo imagético e também os comentários dos leitores. Foram analisadas a frequência das postagens, a quantidade de comentários e o número de seguidores nos blogs.

Ressalta-se que foi identificado que os blogs analisados possuíam tamanhos/proporções muito diferentes como, por exemplo, em relação à quantidade de seguidores e ao número de postagens. Analisar blogs com grandezas distintas tornou-se muito enriquecedor para a pesquisa, 


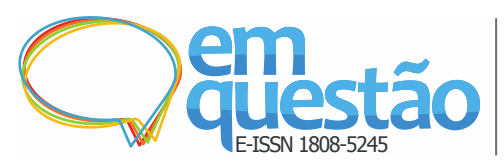

proporcionando, dessa maneira, a compreensão de como ocorrem as práticas informacionais em blogs pequenos, médios e grandes.

A frequência das postagens é diferente em cada blog, uma vez que apresentam diferentes intervalos de tempo na produção de conteúdo. A frequência das postagens pode ser compreendida como um indicativo do tempo de dedicação de cada blogueira ao seu blog, no que diz respeito à produção de conteúdo e a preocupação em mantê-lo sempre atualizado. É perceptível que a maioria dos blogs possui uma frequência média de postagem pré-estabelecida pelas blogueiras: encontrou-se a frequência diária (Entrando Numa Fria), frequência de duas vezes por semana (Marshmallow com Café, DNA Literário, Livros e Sushi) e frequência semanal (Cultura Pocket e Paradise Books). Já os blogs Menina Compassiva e Minha Estante e Muito Mais não possuem uma frequência de postagens, apresentando intervalos de tempo muito grandes entre um post e outro. Há meses em que esses blogs não postam nenhum conteúdo ou postam uma única vez.

O levantamento da quantidade de comentários nas postagens evidenciou que as blogueiras possuem diferentes relações com seus respectivos leitores, sejam eles blogueiros ou não. De modo geral, os blogs Marshmallow com Café, Cultura Pocket e Livros e Sushi possuem grande quantidade de comentários, enquanto que os demais têm as postagens pouco comentadas pelos leitores.

Além de apresentarem diferentes frequências de postagens e número de comentários, os blogs também apresentaram proporções variadas no que se refere à quantidade de seguidores, conforme apresentado no Tabela 1.

Tabela 1 - Número de seguidores das blogueiras nos blogs e nas redes sociais

\begin{tabular}{|c|c|c|c|c|c|}
\hline Blogs & $\begin{array}{c}\mathrm{N}^{0} \text { de } \\
\text { seguidores } \\
\text { no } \\
\text { blog } \\
\end{array}$ & $\begin{array}{c}\mathrm{N}^{0} \text { de } \\
\text { seguidores } \\
\text { no } \\
\text { Instagram }\end{array}$ & $\begin{array}{c}\mathrm{N}^{\mathrm{o}} \text { de } \\
\text { seguidores } \\
\text { no } \\
\text { Facebook } \\
\end{array}$ & $\begin{array}{c}\mathbf{N}^{0} \text { de } \\
\text { seguidores } \\
\text { no } \\
\text { Twitter } \\
\end{array}$ & $\begin{array}{c}\mathrm{N}^{0} \text { de } \\
\text { seguidores } \\
\text { no } \\
\text { YouTube } \\
\end{array}$ \\
\hline Entrando Numa Fria & NI & 9.267 & 10.517 & 5.281 & 202 \\
\hline Minha Estante e Muito Mais & 32 & 809 & 410 & NP & NP \\
\hline Marshmallow com Café & 51 & 3.082 & 122 & NP & NP \\
\hline DNA Literário & NI & 1.777 & 1.322 & 106 & 340 \\
\hline
\end{tabular}




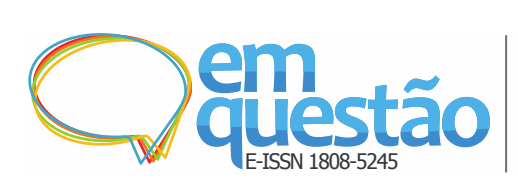

\begin{tabular}{|c|c|c|c|c|c|}
\hline Blogs & $\begin{array}{c}\mathrm{N}^{0} \text { de } \\
\text { seguidores } \\
\text { no } \\
\text { blog } \\
\end{array}$ & $\begin{array}{c}\mathrm{N}^{0} \text { de } \\
\text { seguidores } \\
\text { no } \\
\text { Instagram } \\
\end{array}$ & $\begin{array}{c}\mathbf{N}^{0} \text { de } \\
\text { seguidores } \\
\text { no } \\
\text { Facebook } \\
\end{array}$ & $\begin{array}{c}\mathbf{N}^{0} \text { de } \\
\text { seguidores } \\
\text { no } \\
\text { Twitter } \\
\end{array}$ & $\begin{array}{c}\mathrm{N}^{0} \text { de } \\
\text { seguidores } \\
\text { no } \\
\text { YouTube } \\
\end{array}$ \\
\hline Cultura Pocket & 314 & 659 & 426 & NP & NP \\
\hline Menina Compassiva & 102 & 580 & 449 & 28 & NP \\
\hline Livros e Sushi & 3.881 & 7.774 & 2.922 & 767 & NP \\
\hline Paradise Books & NI & 8.612 & 7.175 & 2.223 & 949 \\
\hline
\end{tabular}

Fonte: Blogs elencados, Instagram, Facebook, Twitter e YouTube adaptados pelos autores. Nota: Informações referentes ao dia 27 de julho de 2018.

Legenda: NI = Não Informado; NP = Não possui

Em relação ao conteúdo foram identificados alguns tópicos semelhantes que caracterizam os blogs literários analisados como: a existência blogs coletivos; a publicação de resenhas de livros; a abordagem de assuntos relacionados à literatura, como filmes e séries; a realização de sorteios; as parcerias com editoras e autores nacionais; a produção de fotografias autorais e intensa presença das blogueiras nas redes sociais (Instagram, Facebook, Twitter, YouTube), conforme apresentado no Tabela 2.

Tabela 2 - Principais características dos blogs literários identificadas na análise documental

\begin{tabular}{|c|c|c|c|c|c|c|c|c|c|c|}
\hline Características & 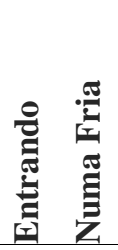 & 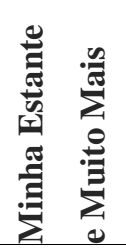 & 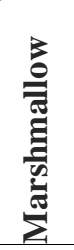 & 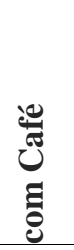 & 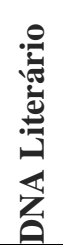 & 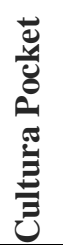 & 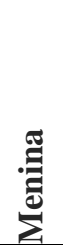 & 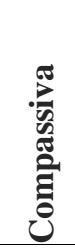 & 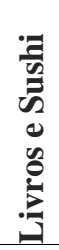 & 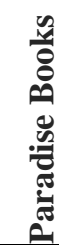 \\
\hline Blog coletivo & $\mathrm{X}$ & & & $\mathrm{X}$ & $\mathrm{X}$ & $\mathrm{X}$ & & & & $\mathrm{X}$ \\
\hline Publica resenha de livros & $\mathrm{X}$ & $\mathrm{X}$ & & $\mathrm{X}$ & $\mathrm{X}$ & $\mathrm{X}$ & & $\mathrm{X}$ & $\mathrm{X}$ & $\mathrm{X}$ \\
\hline $\begin{array}{l}\text { Aborda outros assuntos } \\
\text { como filmes e séries }\end{array}$ & $\mathrm{X}$ & & & $\mathrm{X}$ & $\mathrm{X}$ & $\mathrm{X}$ & & $\mathrm{X}$ & $\mathrm{X}$ & $\mathrm{X}$ \\
\hline Realiza sorteios & $\mathrm{X}$ & $\mathrm{X}$ & & $\mathrm{X}$ & $\mathrm{X}$ & $\mathrm{X}$ & & $\mathrm{X}$ & $\mathrm{X}$ & $\mathrm{X}$ \\
\hline Tem parceria com editoras & $\mathrm{X}$ & & & & $\mathrm{X}$ & & & & $\mathrm{X}$ & $\mathrm{X}$ \\
\hline $\begin{array}{l}\text { Tem parceria com autores } \\
\text { nacionais }\end{array}$ & & $\mathrm{X}$ & & & $\mathrm{X}$ & $\mathrm{X}$ & & & & \\
\hline Produção de fotos autorais & & $\mathrm{X}$ & & $\mathrm{X}$ & $\mathrm{X}$ & $X$ & & $\mathrm{X}$ & $X$ & $X$ \\
\hline
\end{tabular}




\begin{tabular}{|c|c|c|c|c|c|c|c|c|c|c|}
\hline Características & 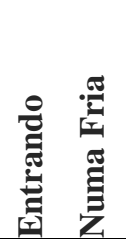 & 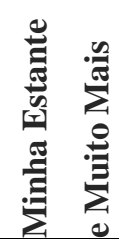 & 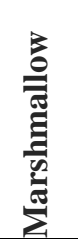 & 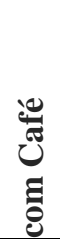 & 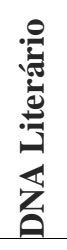 & 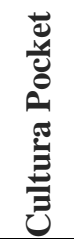 & 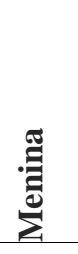 & 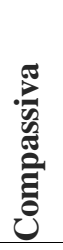 & 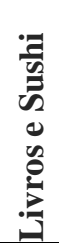 & 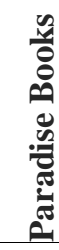 \\
\hline Possui Facebook & $X$ & $\mathrm{X}$ & & $\mathrm{X}$ & $\mathrm{X}$ & $\mathrm{X}$ & $\mathrm{X}$ & x & $\mathrm{X}$ & $\mathrm{X}$ \\
\hline Possui Instagram & $\mathrm{X}$ & $X$ & & $\mathrm{X}$ & $\mathrm{X}$ & $\mathrm{X}$ & $\mathrm{X}$ & $x$ & $\mathrm{X}$ & $\mathrm{X}$ \\
\hline Possui Twitter & $\mathrm{X}$ & & & $\mathrm{X}$ & $\mathrm{X}$ & & $\mathrm{X}$ & $x$ & $\mathrm{X}$ & $\mathrm{X}$ \\
\hline Possui canal no YouTube & $\mathrm{X}$ & & & & $\mathrm{X}$ & & & & & $\mathrm{X}$ \\
\hline
\end{tabular}

Fonte: Elaborado pelos autores.

Dos oito blogs analisados, cinco são coletivos, o que pode demonstrar uma relação de parceria entre os blogueiros e também uma dificuldade em manter atualizado um blog literário de forma individual. A maioria dos blogs também posta resenhas de filmes e séries, de forma que apenas Minha Estante e Muito Mais apresenta-se como exclusivamente literário. A presença das parcerias também é marcante, sendo que quatro blogs possuem parcerias com editoras e cinco com autores nacionais. O blog Menina Compassiva é o único que não possui nenhum tipo de parceria. A produção de fotos autorais dos livros está presente em todos os blogs, com exceção do Entrando Numa Fria. A relação dos blogs com as redes sociais apresenta-se intensa, uma vez que todos os blogs possuem no mínimo dois perfis em redes sociais, e três blogs estão presentes em quatro redes sociais.

Nessa pesquisa, as categorias foram criadas a posteriori, ou seja, emergiram após a análise dos dados das entrevistas. O processo resultou na criação de quatro grandes categorias, com 18 subcategorias, conforme apresentado no Quadro 1.

Quadro 1 - Categorias de análise das práticas informacionais das blogueiras

\begin{tabular}{|l|l|}
\hline Categorias & Subcategorias \\
\hline 6.1 Leitura & 6.1.1 Interesse inicial pela leitura \\
& 6.1.2 Frequência de leitura \\
& 6.1.3 Suportes de leitura \\
& 6.1.4 Necessidade de compartilhar leituras \\
& 6.1.5 Busca de informações sobre livros \\
& 6.1.6 Apropriação da leitura \\
\hline
\end{tabular}




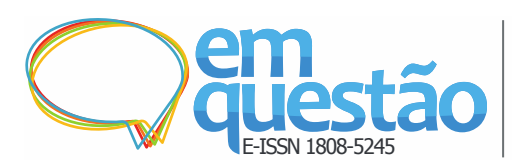

\begin{tabular}{|l|l|}
\hline 6.2 Identidade & 6.2.1 Motivações \\
& $\begin{array}{l}\text { 6.2.2 Representações do blog } \\
6.2 .3 \text { Mudanças após o blog }\end{array}$ \\
\hline 6.3 Ações de informação & 6.3.1 Produção de conteúdo \\
& 6.3.2 Escrita de resenhas \\
\hline & 6.3.3 Sorteios e lançamentos \\
& 6.3.4 Produção de fotos \\
& 6.3.5 Atualização \\
& 6.3 .6 Transmídia \\
\hline 6.4 Interação & 6.4 .1 Leitores \\
& 6.4 .2 Blogueiros \\
& 6.4 .3 Mercado editorial \\
\hline
\end{tabular}

Fonte: Elaborado pelos autores.

As próximas seções serão destinadas a apresentação do conteúdo de cada uma das categorias com suas respectivas subcategorias, nas quais analisou-se o discurso das entrevistadas à luz de abordagens teóricas.

\subsection{Leitura}

A categoria leitura é composta por seis subcategorias. Para conhecer as práticas informacionais das blogueiras no papel de leitoras, considerou-se importante compreender a historicidade da prática da leitura literária, ou seja, como elas se tornaram de fato leitoras. Savolainen (1995) considera que a relação dos sujeitos com a informação é permeada por fatores sociais, culturais, individuais e temporais. Nesse sentido, evidencia-se o fato de que as entrevistadas não se tornaram leitoras de forma arbitrária, mas tiveram uma trajetória histórica permeada de elementos influenciadores em determinado contexto que, juntamente às suas preferências individuais, culminaram na prática da leitura assídua. Ao investigar o interesse inicial das blogueiras pela leitura (6.1.1), identificou-se a presença de pessoas (família, amigos) e instituições (escola, biblioteca) no processo de formação das participantes como leitoras. A família e os professores são frequentemente citados como os principais mediadores de leitura (FAILLA, 2016). Supreendentemente, a literatura de massa influenciou metade das blogueiras, uma vez que elas se tornaram leitoras após lerem o livro best-seller Crepúsculo. Conforme Dumont (2000) a literatura de massa é mais 


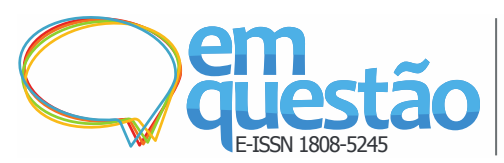

barata e acessível, podendo promover a cultura e a instrução, proporcionando também lazer e descontração para grande parte da população.

A análise da frequência de leitura (6.1.2) considerou sua incorporação ao cotidiano das blogueiras, avaliadas como leitoras assíduas. É perceptível que a frequência de leitura das entrevistadas é variável, uma vez que a maioria das blogueiras relativiza a quantidade de livros que lê em um determinado período de tempo. É evidente que o contato dessas leitoras com os livros é constante, de forma que a leitura foi inserida em suas rotinas. Constata-se que existe no discurso das blogueiras a recordação de um passado no qual elas liam mais ou o destaque para uma época específica do ano em que leem mais livros. Essas falas demonstram um desejo das blogueiras de afirmar que seu desempenho como leitoras pode ser melhor do que relatam no momento, como se quisessem afirmar que conseguem ser leitoras melhores do que são agora.

Quanto aos suportes de leitura (6.1.3), percebeu-se que as blogueiras utilizam o suporte impresso e também o digital, lendo frequentemente ebooks. Carrenho (2016) afirma que os ebooks atraem primeiramente aqueles que já são leitores, pois são eles os mais dispostos a mudar seus hábitos de leitura, sendo mais curiosos em relação aos novos suportes e mais interessados em investir em um aparelho de leitura. As vantagens do livro eletrônico relatadas pelas participantes foram: a facilidade de transporte, a leveza do aparelho, a possibilidade de possuir vários ebooks disponíveis no leitor digital e a rapidez da leitura nesse suporte. Já o livro físico foi lembrado com maior afetividade, como algo para se preservar, colecionar e ler no conforto de casa.

A necessidade de compartilhar leituras (6.1.4) foi evidenciada no discurso de todas as blogueiras, fruto da vontade de conversar e trocar ideias sobre os livros lidos. Todas as blogueiras afirmaram sentir necessidade de compartilhar as suas experiências de leitura. Recomendar o livro lido para os amigos ou fazer uma postagem no blog contando a sua opinião sobre a leitura são modos que essas leitoras encontram de socializar suas leituras. Após a leitura solitária, que propicia a vivência de emoções, a reflexão e a apropriação de informação, essas leitoras necessitam compartilhar essas experiências. Elas 


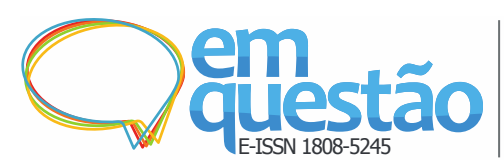

sentem o desejo de interagir com outros que possam ter experienciado essas mesmas leituras ou recomendam que outros leitores também as vivenciem.

A busca de informação sobre livros (6.1.5) pode ocorrer antes e/ou depois da leitura. Muitas dessas buscas ocorrem por meio da web. As blogueiras citaram os blogs, o YouTube, o Skoob e o GoodReads como plataformas nas quais procuram informações sobre livros literários. Contudo, essas buscas nem sempre são realizadas de maneira formal, podendo acontecer informalmente, na forma de conversas com amigos. Desse modo, Savolainen (1995) enfatiza que, muitas vezes, as pessoas procuram por fontes informais de informação. Houve também casos de blogueiras que não sentiram a necessidade de buscar informações. Além disso, foi relatado o encontro casual com o spoiler2. A identificação acidental com a informação está relacionada ao conceito de serendipity cunhado por McKenzie (2003). Para a autora, o encontro casual com a informação tem a mesma importância de uma busca ativa.

Os processos de apropriação da leitura (6.1.6) envolvem a associação do texto literário ao contexto individual de cada leitora, possibilitando o gosto pela leitura, a leitura como fuga da realidade, a vivência da alteridade e as experiências emocionais com a leitura literária. De acordo com Petit (2008), a apropriação da leitura é um assunto individual, relacionado à intimidade, uma vez que “[...] um texto nos apresenta notícias sobre nós mesmos, nos ensina mais sobre nós, nos dá as chaves, as armas para pensarmos sobre nossas vidas, pensarmos nossa relação com o que nos rodeia.” (PETIT, 2008, p. 201).

\subsection{Identidade}

$\mathrm{Na}$ categoria identidade foram identificadas três subcategorias, relacionadas ao envolvimento de cada blogueira com seu blog. Segundo Recuero (2004b), a relação ente o eu do blogueiro e o blog trata-se da apropriação individual do espaço virtual, uma construção do eu em um lugar que é meu, que culmina em uma personalização do blog. Nesse sentido, promoveu-se uma exploração das dimensões emocional e social dos sujeitos da pesquisa, uma vez que acessar e usar a informação é também uma ação emocional, cultural, contextual, não restringindo-se o sujeito a uma mente cognitiva (ARAÚJO, C., 2012). 


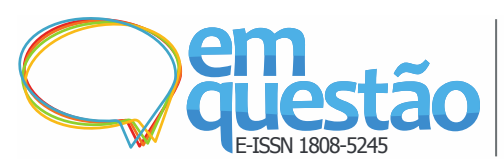

A subcategoria motivações (6.2.1) compreende os principais motivos que levam as leitoras a se apropriarem do ciberespaço, tornando-se blogueiras. É evidente que as motivações das blogueiras, tanto para se inserirem na blogosfera literária como para continuar realizando postagens no blog, perpassam por questões muito pessoais, que envolvem sentimentos muito íntimos como: a necessidade de trabalhar a timidez, ter voz ativa e ser ouvida por outras pessoas, compartilhar suas leituras e poder expressar sua própria opinião, ser um exemplo para os filhos e mantê-los próximos, escapar da solidão, a responsabilidade com as parcerias e com os leitores do blog.

Em representações do blog (6.2.2), compreende-se como as blogueiras concebem o seu próprio blog. Para algumas entrevistadas o blog é um hobby, sendo uma atividade realizada por prazer. Em outros casos é uma forma de visibilidade, principalmente no próprio meio literário. Para outras é um trabalho, pois elas possuem parcerias com editoras e necessitam cumprir prazos para ler os livros recebidos e postar as resenhas. No discurso de metade das blogueiras constatou-se que elas se referem ao blog como um filho, utilizando também a palavra cuidar ao se referirem à atualização do blog. Essas expressões demonstram uma forte afetividade na relação das blogueiras com seu blog.

Na subcategoria mudanças após o blog (6.2.3), algumas blogueiras relatam que o blog possibilitou a criação de novas amizades e melhoria da sociabilidade, outras consideram que trouxe autoconfiança e reconhecimento. É perceptível no discurso das blogueiras que sua inserção na blogosfera literária possibilitou mais do que a participação no universo literário, abrindo caminho para conhecer novas pessoas e fazer amizades, além de permitir a conquista da autoconfiança e um reconhecimento do seu trabalho por parte de terceiros, como os familiares e as editoras. É importante ressaltar que as mudanças observadas por cada blogueira estão relacionadas a sentimentos muito íntimos, que envolvem as relações interpessoais, a capacidade de interagir, a confiança em si mesma e a sensação de ser reconhecida.

\subsection{Ações de Informação}

A categoria ações de informação compreende seis subcategorias. Em sua pesquisa, Harlan (2012) considera como ações de informação: a coleta, o 


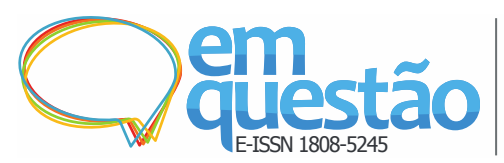

pensamento e a criação de conteúdo. Ao fazer um paralelo com o conceito de ações de informação proposto por Harlan (2012), a presente categoria intenciona compreender as ações das blogueiras no processo de produção de conteúdo para o blog. Tal processo compreende ações de coleta, visto que as blogueiras necessitam de realizar leituras prévias para produzir resenhas, procurar informações sobre os lançamentos ou recebê-las diretamente das editoras. As ações de pensamento também estão presentes no momento da construção do texto, no planejamento dos sorteios, na ideia do cenário das fotografias de livros, ao manter a atualização do blog, ao programar a divulgação do conteúdo em cada uma das redes sociais. As ações de criação são contempladas no ato de escrever resenhas críticas, realizar sorteios, divulgar lançamentos literários, fotografar livros, postar nas redes sociais, enfim, produzir conteúdo.

A subcategoria produção de conteúdo (6.3.1) contém a visão das próprias blogueiras da sua atuação em relação a criação de publicações no blog. De acordo com Arnaut et al. (2011), atualmente, todos têm o potencial de produzir conteúdo. A maioria se considera produtora de conteúdo, as demais consideram que compartilham informações e emitem opiniões, o que também pode ser compreendido como forma de produção de conteúdo.

Em escrita de resenhas (6.3.2) compreende-se a relação das blogueiras com a escrita e a produção das resenhas críticas, processo permeado por várias questões: a leitura do livro; a organização das ideias; o ato de escrever em si, com as preocupações com as normas da língua portuguesa; a edição do texto; a revisão; a expressão dos sentimentos; a emissão de opiniões, a exposição da blogueira; a transmissão de informações.

$\mathrm{Na}$ subcategoria sorteios e lançamentos (6.3.3) percebe-se que o conteúdo dos blogs literários não é unicamente voltado para as resenhas críticas de livros, sendo produzidas também outras formas de publicações que diversificam as postagens, como forma de chamar a atenção dos leitores e de trazer novidades. Os sorteios de livros são feitos por todas as blogueiras entrevistadas, muitas vezes a divulgação do sorteio é feita no blog e/ou nas redes sociais, intencionando trazer novos leitores para o blog. Ao noticiar o lançamento de um livro, as blogueiras se sentem importantes, uma vez que 


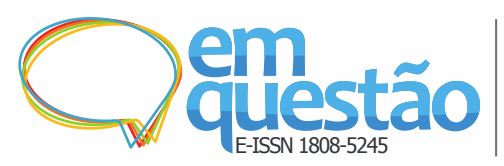

receberam aquela informação em primeira mão, sendo as responsáveis por transmiti-la ao público.

Em produção de fotos (6.3.4) constata-se a forte tendência das fotografias autorais feitas pelas blogueiras, que envolve dedicação e até mesmo investimento financeiro, o que evidencia uma necessidade de se produzir um outro tipo de conteúdo, além da informação textual. Conclui-se que a disseminação de informações sobre os livros lidos também ocorre por meio das fotografias.

A importância da atualização (6.3.5) do blog para as blogueiras foi investigada, uma vez que é um dos atributos determinantes de um blog, visto que são organizados em função do tempo e caracterizam-se pela inserção frequente de posts (RECUERO, 2004a; DI LUCCIO; NICOLACI-DA-COSTA, 2010; MARQUES, 2012). Percebe-se que todas as blogueiras evidenciam a atualização, tendo consciência do seu papel preponderante na permanência dos seguidores. Afinal, a ausência de novas postagens provoca a frustração do leitor, dificultando o acompanhamento do blog.

Na subcategoria transmídia (6.3.6), observa-se o uso das redes sociais (Instagram, Facebook, Twitter e YouTube) como plataformas vinculadas ao blog, destacando o Instagram como a mídia mais atrativa na visão das blogueiras. Conforme Arnaut et al. (2011), é essencial o conhecimento das plataformas de mídia, sabendo-se utilizar o melhor de cada uma de modo que elas se complementem. No caso das entrevistadas, o uso das plataformas se torna complementar na medida em que o blog é o espaço preferencial para a postagem das resenhas de forma integral, para personalização da identidade da blogueira e marca do seu lugar no ciberespaço; já o Instagram torna-se apoio do blog na divulgação das resenhas e na postagem de fotografias atrativas dos livros. O Facebook não está sendo considerado pelas blogueiras como uma rede muito acessada, entretanto, foram relatadas algumas facilidades no uso da rede social, como o envio automático da postagem feita no blog e a facilidade de interação com as pessoas. O Twitter é uma rede social pouco usada pelas blogueiras, apesar de a maioria possuir uma conta do seu respectivo blog. Algumas entrevistadas relatam dificuldade no uso da rede social, havendo 


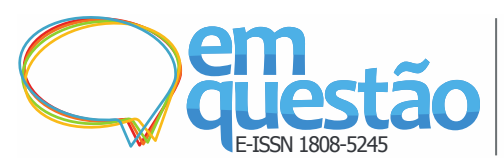

poucos casos de blogueiras que usam constantemente o Twitter. Com exceção da blogueira do DNA Literário, as participantes mostram-se desmotivadas a produzir conteúdo para o YouTube, sendo os motivos citados: a dificuldade de edição, a administração de várias mídias, a ascendência do Instagram no meio literário, ausência de retorno financeiro e exposição pessoal.

\subsection{Interação}

Nas investigações de práticas informacionais, Ilemar Berti e Carlos Araújo (2017) enfatizam que a interação caracteriza a complexidade do sujeito, pertencente a dimensões individuais, coletivas, sociais e culturais. De fato, a interação é o conceito chave da abordagem social dos estudos de usuários da informação, significando uma ação recíproca, colocando em relevo o fato de uma ação ou influência sobre algo também ser afetada por esse algo. Nesse sentido, podemos analisar a relação recíproca do sujeito com o contexto, a informação, o coletivo (ARAÚJO, C., 2012).

A categoria interação discute as práticas informacionais das blogueiras entrevistadas ao interagirem com os leitores de seus respectivos blogs, com outros blogueiros da blogosfera literária e também com o mercado editorial, composto pelos autores nacionais e pelas editoras.

Ao investigar a relação das blogueiras com seus leitores (6.4.1), por um lado, percebe-se a importância do número de seguidores, por outro lado, a ausência de vínculo com os leitores na maior parte dos casos. A relevância dos comentários é evidenciada, além de existir um discurso comum sobre a ausência de comentários nos blogs, motivo de angústia para muitas blogueiras. Ressaltase que as blogueiras realizam, de certa forma, um incentivo à leitura em seus blogs, ao indicarem e divulgarem livros, influenciando outros blogueiros e leitores a lerem. Entretanto, tal incentivo não pode ser considerado uma mediação de leitura, devido à ausência de uma relação próxima entre as blogueiras e seus leitores na maior parte dos casos.

$\mathrm{Na}$ análise da interação entre as blogueiras e os demais blogueiros (6.4.2), metade das entrevistadas fazem leitura de outros blogs, já a outra metade acompanha somente perfis do Instagram de blogueiros literários. A influência 


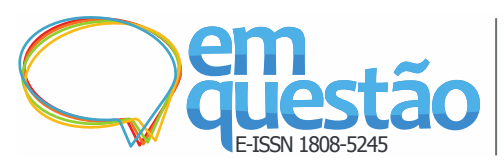

entre os blogueiros é evidente no momento que antecede a leitura, na escolha do livro e na sua aquisição; além da influência no próprio blog, no formato das publicações e nos conteúdos postados. A investigação sobre a formação dos webrings evidencia que, de modo geral, os círculos de blogueiros não se formam somente como indicado no referencial teórico (RECUERO, 2003). Verificou-se que, em grande parte dos casos, os webrings formam-se tanto de forma virtual como presencialmente, por meio dos eventos literários. A discussão sobre os webrings pertencentes à blogosfera literária ressaltou a interação entre blogueiros literários, o compartilhamento de informação e as trocas comunicativas que ocorrem dentro desses círculos sociais. Entretanto, a interação entre blogueiros acontece predominantemente no meio virtual, por meio das diversas mídias sociais. Os eventos literários são compreendidos como pontos de encontros de leitores, sendo muito estimado pelas blogueiras, como forma de promover a sociabilidade. Quanto aos sentimentos presentes na relação entre blogueiros, de um lado, a amizade e a cooperação; do outro, a competição e os conflitos.

Por fim, ao compreender a relação das blogueiras com o mercado editorial (6.4.3), encontrou-se duas formas de parceria: com editoras e com autores nacionais. As blogueiras têm consciência de que a parceria editorial se trata de uma estratégia de marketing das editoras, mesmo assim elas desejam as parcerias, alegando que promovem credibilidade, atualização do conteúdo do blog e maior divulgação das postagens. Quanto à parceria com autores nacionais, existe uma relação de cooperação, uma vez que as blogueiras têm maior proximidade com os escritores, sentindo vontade de ajudá-los com a divulgação dos livros de sua autoria e receio de ofendê-los por meio das resenhas críticas.

\section{Considerações Finais}

Com base no objetivo geral da pesquisa, investigar os blogs literários buscando averiguar as práticas informacionais dos blogueiros no que diz respeito aos seus papéis como produtores de conteúdo, leitores e mediadores de leitura nos webrings pertencentes à blogosfera literária, considera-se que o mesmo foi 


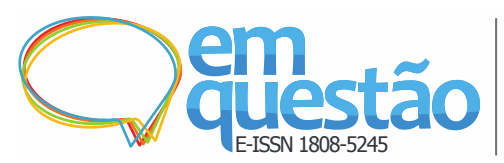

alcançado. Conclui-se que as práticas informacionais realizadas pelas blogueiras literárias, elencadas em quatro grandes categorias - leitura, identidade, ações de informação e interação - refletem o modo como as blogueiras lidam com a informação do seu próprio ponto de vista, nos processos de necessidade, busca, uso, apropriação, produção e compartilhamento, que se encontram socialmente inseridos.

No que tange ao primeiro objetivo específico, caracterizar as práticas informacionais dos blogueiros literários, a análise dos dados da pesquisa possibilitou compreender as práticas informacionais das blogueiras identificadas na amostra, que foram discutidas nas categorias principais e subcategorias.

O segundo objetivo específico, constatar os principais motivos que levam à criação do blog literário, foi contemplado na subcategoria 6.2.1, que apresenta as motivações para inserção na blogosfera literária e também as motivações para postar no blog, mantendo-o ativo. As motivações são diversas, possuindo caráter pessoal, indo além da necessidade de compartilhar leituras.

O terceiro objetivo específico propunha a identificação dos papéis dos blogueiros literários como leitores, produtores de conteúdo e mediadores de leitura. Com base na análise das entrevistas, os papéis de leitoras e produtoras de conteúdo foram caracterizados como as principais atuações das blogueiras na blogosfera literária, já que elas objetivam ler livros literários e compartilhar conteúdo na web, seja no formato imagético ou textual. A caracterização das blogueiras como leitoras é discutida em toda a categoria 6.1, referente à leitura. A temática das blogueiras como produtoras de conteúdo é abordada na subcategoria 6.3.1, que apresenta a visão das próprias blogueiras sobre esse papel. Diagnosticou-se que as blogueiras não atuam no papel de mediadoras de leitura, uma vez que não possuem proximidade suficiente com seus leitores para realizar de fato uma mediação, atuando apenas no incentivo à leitura dos livros que recomendam, conforme discutido na subcategoria 6.4.1.

O último objetivo específico, a investigação de como se dá a criação dos webrings, foi contemplado na subcategoria 6.4.2. A discussão sobre os webrings pertencentes à blogosfera literária ressaltou a interação entre blogueiros literários, o compartilhamento de informação e as trocas comunicativas que 


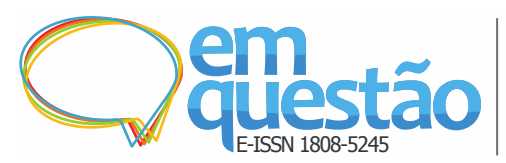

ocorrem dentro desses círculos sociais. Verificou-se que, em grande parte dos casos, os webrings formam-se tanto de forma virtual como presencialmente, por meio dos eventos literários. Entretanto, a interação entre blogueiros acontece predominantemente no meio virtual, por meio das diversas mídias sociais.

Como pesquisas complementares e futuras, sugere-se o estudo das práticas informacionais dos blogueiros literários com ênfase no fenômeno transmídia, investigando o uso e apropriação das diversas redes sociais como forma de produzir e compartilhar informações vinculadas ao universo literário, verificando também a interatividade. Outra possibilidade de pesquisa futura seria explorar as práticas informacionais dos blogueiros especificamente durante os eventos literários, acompanhando com maior proximidade as interações entre blogueiros que ocorrem presencialmente. As comunidades de leitores formadas nos sites Skoob, Whattpad e Goodreads, visando o compartilhamento de leituras na web, também podem ser alvo de pesquisas sobre práticas informacionais.

\section{Agradecimentos}

À Coordenação de Aperfeiçoamento de Pessoa de Nível Superior (CAPES) pelo apoio financeiro à dissertação da qual se origina esse artigo. Às blogueiras literárias participantes da pesquisa, por terem compartilhado conosco suas experiências literárias e suas vivências na blogosfera.

\section{Referências}

ARAÚJO, Carlos Alberto Ávila. Estudos de usuários: pluralidade teórica, diversidade de objetos. In: ENCONTRO NACIONAL DE PESQUISA EM CIÊNCIA DA INFORMAÇÃO, 9., 2008, Cidade São Paulo. Anais [...]. São Paulo: USP, 2008. Disponivel em: http://enancib.ibict.br/index.php/enancib/ixenancib/index. Acesso em: 7 jul. 2019.

ARAÚJO, Carlos Alberto Ávila. Paradigma social nos estudos de usuários da informação: abordagem interacionista. Informação \& Sociedade, João Pessoa, v. 22 , n. 1 , p. 145-159, 2012.

ARAÚJO, Rafaela Lima de; ARAÚJO, Ronaldo Ferreira de. Ler, compartilhar e interagir: blogs como ferramenta de mediação de leitura. Revista ACB, Florianópolis, v. 20, n. 2, p. 240-260, maio/ago. 2015. 
ARNAUT, Rodrigo Dias et al. A Era Transmídia. Revista Geminis, São Carlos, v. 2, n. 2, p. 259-275, 2011.

BERTI, Ilemar Christina Lansoni Wey; ARAÚJO, Carlos Alberto Ávila.

Estudos de usuários e práticas informacionais: do que estamos falando?

Informação \& Informação, Londrina, v. 22, n. 2, p. 389- 401, maio/ago. 2017.

BÉRTOLO, Constantino. O banquete dos notáveis: sobre leitura e crítica. São Paulo: Livros da Matriz, 2014.

CAPURRO, Rafael. Epistemologia y Ciencia de la Informacion. In:

ENCONTRO NACIONAL DE PESQUISA EM CIÊNCIA DA

INFORMAÇÃO, 5., 2003, Belo Horizonte. Anais [...]. Belo Horizonte: ECI,

2003.

CARNEIRO, Jéssica de Souza. Ler e escrever blogs literários: a narrativa hipertextual na configuração da webliteratura. 2011. Dissertação (Mestrado em Estudos Literários) - Instituto de Letras e Comunicação, Universidade Federal do Pará, Belém, 2011.

CARRENHO, Carlo. O que os livros digitais representam para o aumento da leitura? O que diz a retratos da leitura sobre quem lê nesse suporte? In:

FAILLA, Zoara (org.). Retratos da leitura no Brasil 4. Rio de Janeiro:

Sextante, p. 99-112, 2016.

DI LUCCIO, Flávia; NICOLACI-DA-COSTA, Ana Maria. Blogs: de diários pessoais a comunidades virtuais de escritores/leitores. Psicologia Ciência e Profissão, Rio de Janeiro, v. 30, n. 1, p. 132-145, 2010.

DUMONT, Lígia Maria Moreira. A opção pela literatura de massa: simples lazer, ou alienação? Investigación Bibliotecológica, México, v. 14, n. 28, p. 166-177, jun. 2000.

FAILLA, Zoara (org.). Retratos da Leitura no Brasil 4. Rio de Janeiro: Sextante, 2016.

FRANCO, Maria Laura Puglisi Barbosa. Análise de conteúdo. 2. ed. Brasília: Liber Livro, 2005.

GNISCI, Vanessa Monteiro Ramos. Booktubers: narrativas e experiências literárias da juventude contemporânea. Textura, Canoas, v. 20, n. 42, p. 106124, jan./abr. 2018.

GUERRA, Isabel Carvalho. Pesquisa qualitativa e análise de conteúdo: sentidos e formas de uso. Cascais: Principia, 2006.

HARLAN, Mary Ann. Information practices of teen content creators: the intersection of action and experiences. A grounded theory study. 2012. Thesis 
(Doctor of Philosophy) - School of Information Systems, Science and Engineering Faculty, Queensland University of Technology, Queensland, 2012.

KOZINETS, Robert. The field behind the screen: using netnography for marketing research in online communities. Journal of Marketing Research, [s.l] n. 39, p. 61-72, feb. 2002.

MARQUES, Márcia Siqueira Costa. O blog como meio de comunicação: origem, apropriações e horizontes da blogosfera na sociedade contemporânea. 2012. Tese (Doutorado em Comunicação e Semiótica) - Pontifícia Universidade Católica de São Paulo, São Paulo, 2012.

MCKENZIE, Pamela. A model of information practices in accounts of everyday: life information seeking. Jornal of Documentation, Bingley, v. 59, n. 1, p. 19-40, 2003.

PEREIRA, Maria Leopoldina. Blogs literários como gênero do discurso: contribuição para a formação do leitor/autor. In: SIMPÓSIO HIPERTEXTO E TECNOLOGIAS NA EDUCAÇÃO, 2., 2008, Recife. Anais [...] Recife: Universidade Federal de Pernambuco, 2008. Disponível em: http://www.nehte.com.br/simposio/anais/simposio2008.html. Acesso em: 7 jul. 2019.

PETIT, Michèle. A arte de ler ou como resistir à adversidade. São Paulo: Editora 34, 2009.

PETIT, Michèle. Os jovens e a leitura. São Paulo: Editora 34, 2008.

RECUERO, Raquel da Cunha. Weblogs, webrings e comunidades virtuais. Revista 404notFound, v. 1, n. 31, 2003. Disponível em: http://www.raquelrecuero.com/webrings.pdf. Acesso em 7 jul. 2019.

RECUERO, Raquel da Cunha. O interdiscurso positivo como característica fundamental dos webrings. Intexto, Porto Alegre, v. 1, n. 10, p. 1-16, 2004a.

RECUERO, Raquel da Cunha. Webrings: as redes de sociabilidade e os weblogs. Sessões do Imaginário, Porto Alegre, v. 9, n. 11, p. 19-27, 2004 b.

SANTOS, Francielle Couto; RODRIGUES, Érika Letícia de Oliveira; FERREIRA, Raquel Marques Carrico. Blogs literários: investigações sobre audiência a partir da perspectiva de usos e gratificações. Leituras do Jornalismo, São Paulo, v. 1, n. 2, p. 101-114, 2014.

SAVOLAINEN, Reijo. Everyday life information seeking: approaching information seeking in the context of "way of life". Library \& Information Science Research, Amsterdam, v. 17, n. 3, p. 259-294, 1995.

SAVOLAINEN, Reijo. Information behavior and information practice: 
reviewing the "umbrella concepts" of information-seeking studies. Library Quarterly, Chicago, v. 77, n. 2, p. 109-132, 2007.

SILVA, Olga Ozaí; MARTHA, Alice Áurea Penteado. A interação na leitura em blogs e sua mediação na formação de jovens leitores. In: FÓRUM INTERNACIONAL DE LEITURA E LITERATURA INFANTIL E JUVENIL, 2., 2010, Porto Alegre. Anais [...]. Porto Alegre: PUCRS, 2010. Disponível em: http://ebooks.pucrs.br/edipucrs/anais/IICILLIJ/. Acesso em: 7 jul. 2019.

SIRIHAL DUARTE, Adriana Bogliolo; ARAUJO, Carlos Alberto Ávila; PAULA, Cláudio Paixão Anastácio de. Práticas informacionais: desafios teóricos e empíricos de pesquisa. In: ENCONTRO INTERNACIONAL DE USOS E USUÁRIOS DA INFORMAÇÃO, 1., 2017, Fortaleza. Anais [...]. Fortaleza: Universidade Federal do Ceará, 2017. Disponível em: http://www.eneu2017.ufc.br/index.php/eneu/1/schedConf/presentations. Acesso em 7 jul. 2019.

SPOILER. In: Dicionário Priberam da Língua Portuguesa. [S. l.]: Priberam Informática, 2018. Disponível em: https://dicionario.priberam.org/spoiler. Acesso em: 19 set. 2018.

\title{
Information Practices of Literary Bloggers
}

\begin{abstract}
In this article we present the results of an investigation that sought to ascertain the information practices of bloggers regarding their roles as readers, content producers, and reading mediators in the webrings - the social circles of bloggers - belonging the literary blogosphere. Since the research was qualitative and in depth, the methodology involved the use of netnography, which allowed an immersion in the literary blogosphere, using the documentary analysis and the semi-structured interview as data collection techniques. The results pointed out the information practices performed by the eight bloggers identified in the sample, which were listed in four categories: reading, identity, information actions, and interaction. Regarding the roles played by the bloggers in the literary blogosphere, it was identified that they act as readers and as content producers but are not considered mediators of reading, although they encourage reading on their blogs. The motivation of each blogger both to enter the literary blogosphere and to keep their blog active runs through personal matters that extend beyond the simple desire to share readings: the need to overcome shyness, to have an active voice, and to be heard by other people, as well as being able to express their own opinion about the readings, set an example for their children and keep them close, escape from loneliness, and the responsibility for editorial partnerships and blog readers. Regarding the formation of webrings, it was verified that they are formed both in virtual and in person, through literary events. However, the interaction between literary bloggers occurs predominantly in the virtual environment.
\end{abstract}


Keywords: Information Practices. Literary Blogs. Bloggers. Webrings. Sharing readings.

Recebido: 19/11/2018

Aceito: 11/06/2019

1 Pesquisa registrada pelo Comitê de Ética em Pesquisa da Universidade Federal de Minas Gerais. Número de registro de CAAE: 87252618.0.0000.5149.

2 Informação que revela partes importantes do enredo de um filme, de uma série televisiva ou de um livro, sobretudo para quem ainda não os viu ou leu (SPOILER, 2018). 